\title{
Prevalence and risk factors of low back pain and disability index among operating room nurses
}

Follow this and additional works at: https://www.journal.acorn.org.au/jpn

Part of the Health Services Administration Commons, Health Services Research Commons, Perioperative, Operating Room and Surgical Nursing Commons, and the Surgery Commons

(c) (i)

This work is licensed under a Creative Commons Attribution 4.0 License.

\section{Recommended Citation}

Jeyakumar, Anita Kiruba and Segaran, Florence (2018) "Prevalence and risk factors of low back pain and disability index among operating room nurses," Journal of Perioperative Nursing: Vol. 31 : Iss. 3 , Article 3. Available at: https://doi.org/10.26550/2209-1092.1030

https://www.journal.acorn.org.au/jpn/vol31/iss3/3

This Article is brought to you for free and open access by Journal of Perioperative Nursing. It has been accepted for inclusion in Journal of Perioperative Nursing by an authorized editor of Journal of Perioperative Nursing. 


\section{Authors}

Anita Kiruba Jeyakumar

Christian Medical College, Vellore

Florence Segaran

Christian Medical College, Vellore

\section{Corresponding author}

Anita Kiruba Jeyakumar

Christian Medical College, Vellore anitajeyakumar0906@gmail.com

\section{Prevalence and risk factors of low back pain and disability index among operating room nurses}

\section{Introduction}

Low Back Pain (LBP) is one of the most common complaints requiring medical attention and is the most common form of musculoskeletal disorder ${ }^{1,2}$. It is estimated that over half of the general population will seek medical care for back pain at some point in their lives ${ }^{3}$. Globally, the prevalence of LBP among the general population ranges between 15 and 45 per cent ${ }^{1,2,4,5}$.

Occupational LBP is a common health problem worldwide. Health care workers (HCWs) are at a higher risk of developing LBP due to a variety of factors ${ }^{6}$. This problem is associated with major consequences in terms of disability and frequent absence $^{6}$. LBP may lead to activity limitation and sick leave for more than 50 per cent of nurses?. Female gender, advanced age and high Body Mass Index (BMI) are some examples of risk factors commonly associated with LBP $^{8-13}$. Sport and regular physical activity were found to decrease $\mathrm{LBP}^{14}$. Working in the operating room (OR) carries its own risk for developing LBP due to exposure to additional risk factors such as prolonged standing and awkward posture during surgeries ${ }^{6,15-17}$.

There are several studies that have been carried out to assess the prevalence of and risk factors for LBP in OR personnel. Since the operating room is a dynamic place of work, research into risk factors for LBP in OR personnel must be comprehensive in terms of work environment, body mechanics and OR work routine. This will provide a panorama for risk factors for LBP.

\section{Background}

Work-related LBP poses a major health and socioeconomic problem in modern society. Globally, LBP is a significant occupational hazard in the health care profession. Among hospital-based health care workers, the cumulative life prevalence of LBP is 72.5 per cent and the yearly prevalence is 56.9 per cent ${ }^{18}$. Treatment is sought by 34.1 per cent of health care workers suffering from LBP, out of which 7.3 per cent require sick leave or absences from work.

A study conducted to assess the prevalence of LBP among nurses in the same tertiary care centre in India revealed that 92 per cent of nurses had LBP and ten per cent of those had taken sick leave of more than 15 days per year due to LBP.

This study allows us to determine the prevalence of and risk factors for LBP among OR personnel and also provides an overall picture regarding the disability index among them. This study will also provide pilot data for future studies that will determine the effectiveness of interventions to reduce LBP among OR personnel. Our long-term goal is to modify these risk factors and improve the work productivity among OR nurses which will eventually positively influence the quality of patient care. 


\section{Aim}

The study aimed to:

- assess the prevalence of LBP among OR nurses working at a tertiary care centre in a developing country

- assess the risk factors for LBP specific to OR nurses in a developing country

- identify the disability index among those OR nurses with LBP.

\section{Participants/ethics}

The study had institutional review board approval from Christian Medical College, Vellore, Tamil Nadu, South India. All levels of nurses working in the department of OR nursing were included for recruitment. Nurses with less than one year of experience were exempted from this study. Participant numbers identified those eligible nurses. All eligible nurses who completed the survey form consented to voluntarily participation in the study.

\section{Survey/sampling}

The study was a cross-sectional survey carried out among OR nurses at Christian Medical College, which is a 2600-bed hospital located in the suburbs of Vellore in the state of Tamil Nadu, India. The hospital is a tertiary medical centre with 37 operating rooms in three different locations within the hospital premises. There are 28 operating rooms, with 237 registered nurses (RNs) and multipurpose health workers in the main OR, seven operating rooms with 51 RNs and multipurpose health workers in the centenary building OR (CBOR), and two operating rooms with 14 RNs and multipurpose health workers in the day care OR. The main OR caters to all adult surgical specialities except obstetrics and gynaecology
(OBG). The CBOR caters to paediatric specialties along with $\mathrm{OBG}$ and the reproductive medicine and surgery unit. The day care OR serves as an ambulatory care centre for all minor surgical interventions. There are a total of 302 nurses at all levels working in the department of OR nurses in the Christian Medical college.

The instrument used for data collection was a self-structured questionnaire developed by the investigator and validated by a jury of experts (two nurses and a physical therapist) involved in the management of LBP from the department of physical therapy at Kansas University Medical Center, Kansas City, Kansas, USA. The questionnaire sought demographic details and duty schedules of participants as well as information about back hygiene and prevalence, onset, duration, severity, causes, management and contributing factors of LBP. The construct and content validity of the survey assessed by two practicing OR nurses and two research experts on LBP in the physiotherapy department at Kansas University Medical Center provided a content validity index of 0.97. Along with this questionnaire, a Modified Oswestry Low Back Pain Disability Questionnaire was also administered which assessed how back pain affected the everyday life of OR nurses.

During a weekly OR nurses meeting, the study was presented to the nurses. Volunteers who fitted the inclusion criteria and who were willing to take part were invited to register within a given deadline. At the end of the deadline 250 nurses had registered. The survey was administered to the participants for a week at the end of their shifts and data was gathered.

\section{Data analysis}

The coded response on the questionnaire was entered onto computer general purpose coding forms. The data were analysed using the Statistical Package for Social Sciences (SPSS) (Windows Version 10.0 Chicago IL, USA). The results were presented using simple percentage, mean and standard deviation (SD). A chi-squared test $\left(X^{2}\right)$ was used to determine the association between variables. A probability level of 0.05 or less was used to indicate statistical significance.

\section{Results}

The majority of the 250 respondents answered all of the questions on the questionnaire. Of the OR nurses who registered, 220 (88 per cent) were women, 108 (43.2 per cent) were between the ages of 20 and 30 years and 197 (78.8 per cent) were in scrubbing or circulating roles. OR nurses from the orthopaedic surgical unit were the highest in number with 36 respondents ( 14.4 per cent). The participants with one to five years of experience in OR made up the majority group. Demographics of the respondents are presented in Table 1.

As shown in Table 2, the mean height of the study population was $152.2 \mathrm{~cm}$, with a standard deviation of 0.76 , and the mean weight was $55.3 \mathrm{~kg}$ with a standard deviation of 1.20 .

\section{Prevalence of LPB among OR nurses working in a developing country}

Among the 250 respondents, 210 (84 per cent) of them experienced LBP at least once during the past year. This study also brought out the surprising revelation that 79.6 per cent (199) of the respondents with LBP had developed it after joining nursing. 
Table 1: Demographic details of participants $(\mathrm{N}=250)$

\begin{tabular}{|c|c|c|}
\hline $\begin{array}{l}\text { Demographic } \\
\text { feature }\end{array}$ & & $\mathrm{n}$ \\
\hline \multirow[t]{2}{*}{ Marital status } & Married & $167(66.8 \%)$ \\
\hline & Single & $83(33.2 \%)$ \\
\hline \multirow{5}{*}{ Education } & Certificate & $41(16.4 \%)$ \\
\hline & Diploma & $194(77.6 \%)$ \\
\hline & Degree & $15(6.0 \%)$ \\
\hline & Additional or advanced degree in OR nursing & $18(7.2 \%)$ \\
\hline & $\begin{array}{l}\text { No additional or advanced degree in OR } \\
\text { nursing }\end{array}$ & $232(92.8 \%)$ \\
\hline \multirow{5}{*}{$\begin{array}{l}\text { Years of } \\
\text { experience in } \\
\text { the current } \\
\text { occupation }\end{array}$} & $1-5$ & $104(41.6 \%)$ \\
\hline & $6-10$ & $65(26.0 \%)$ \\
\hline & $11-20$ & $65(26.0 \%)$ \\
\hline & $21-25$ & $10(4.0 \%)$ \\
\hline & $>25$ & $6(2.4 \%)$ \\
\hline \multirow{8}{*}{$\begin{array}{l}\text { OR where } \\
\text { currently } \\
\text { working }\end{array}$} & General surgery & $29(11.6 \%)$ \\
\hline & Orthopaedic and trauma & $44(17.6 \%)$ \\
\hline & Urology & $21(8.4 \%)$ \\
\hline & Neurology & $16(6.4 \%)$ \\
\hline & Cardiothoracic & $27(10.8 \%)$ \\
\hline & Emergency & $16(6.4 \%)$ \\
\hline & ENT / Plastic surgery / Dental & $36(14.4 \%)$ \\
\hline & Paediatric surgery & $33(13.2 \%)$ \\
\hline
\end{tabular}

Table 2: Distribution of study population according to height and weight $(\mathrm{N}=250)$

\begin{tabular}{|c|c|c|c|c|}
\hline Variables & & $\mathrm{n}$ & Mean & $\begin{array}{l}\text { Standard } \\
\text { deviation }\end{array}$ \\
\hline \multirow[t]{5}{*}{ Height (cm) } & $130-140$ & $4(1.6 \%)$ & \multirow[t]{5}{*}{$152.2 \mathrm{~cm}$} & \multirow[t]{5}{*}{0.76} \\
\hline & $141-150$ & 56 (22.4\%) & & \\
\hline & $151-160$ & $141(56.4 \%)$ & & \\
\hline & $161-170$ & $41(16.4 \%)$ & & \\
\hline & $>170$ & $8(3.2 \%)$ & & \\
\hline \multirow[t]{6}{*}{ Weight (kg) } & $30-40$ & $13(5.2 \%)$ & \multirow[t]{6}{*}{$55.3 \mathrm{~kg}$} & \multirow[t]{6}{*}{1.2} \\
\hline & $41-50$ & $48(19.2 \%)$ & & \\
\hline & $51-60$ & 78 (31.2\%) & & \\
\hline & $61-70$ & $67(26.8 \%)$ & & \\
\hline & $71-80$ & $34(13.6 \%)$ & & \\
\hline & $>80$ & $10(4.0 \%)$ & & \\
\hline
\end{tabular}

Risk factors for LBP in OR nurses in a developing country

The data analysis showed significant association between LBP and the following factors:

- incorrect body mechanics $(p<0.01)$

- surgical unit where working $(p<0.05)$

- stressful work conditions $(p<0.05)$

- assisting in positioning patients for surgery $(p<0.01)$

- assisting in transferring patients $(p<0.05)$

- strenuous nature of work $(p<0.05)$

- fatigue in the workplace $(p<0.05)$

- work postures (like bending forward, twisting the torso while assisting), lifting heavy instrument sets and prolonged standing $(p<0.05)$

- stressful workplace $(p<0.01)$.

Level of disability due to LBP among OR nurses in a developing country

LBP causes an array of physical disabilities among those affected. The analysis of data gathered using the modified Oswestry questionnaire revealed that 50.4 per cent (126) of respondents were minimally disabled by LBP and 24 per cent (60) of them were moderately disabled.

\section{Discussion}

In this study 84 per cent of OR nurses reported to have mild, moderate or severe LBP over the past year. This concurs with the worldwide prevalence of LBP among the general population, which is reported to be around 84 per cent. It was also found that females in this study complained more of LBP when compared with males. This is supported by the literature. Globally, nurses are found to have the highest prevalence of $\mathrm{LBP}^{17,9,20 \text {. }}$ 
The relationship between LBP and certain factors was found to be statistically significant - incorrect body mechanics $(p<0.01)$, the surgical unit where a nurse is working ( $p<0.05)$, stressful work conditions $(p<0.05)$, assisting in positioning the patients for surgery $(p<0.01)$, assisting in transferring patients $(p<0.05)$, strenuous nature of work $(p<0.05)$, fatigue at the workplace $(p<0.05)$. This finding is supported by other studies.

OR nurses usually perform certain activities on a daily basis that are significantly associated with and increase the risk of developing LBP. These may include lifting heavy objects above the waist, transferring patients onto a trolley or table, repositioning patients, pulling a patient up the bed and rotating the torso while bearing weight. In the current study, we found that some such activities were indeed significantly associated with LBP, and this is consistent with the other studies. According to the Association for Advancement of Medical Instrumentation (AAMI) standards, an instrument set must not weigh over $5.4 \mathrm{~kg}$. Measures can be taken to de-bulk sets. Trays in which instruments are carried can be replaced with lighter material. Also proper transportation equipment must be provided to avoiding lifting heavy objects above waist level.

Most of the participants developed LBP after joining nursing. This draws attention to the need to increase awareness among OR nurses regarding correct body mechanics and stress management during the early years of nursing training.

The participants in this study have reported that rest and analgesics are best to relieve LBP. Studies on the same topic have drawn the same conclusion.

\section{Conclusion}

The prevalence of LBP among the OR nurses surveyed was 84 per cent. The Oswestry disability index score revealed that 24 per cent of the OR nurses were moderately disabled by LBP. It is anticipated that these findings will highlight the need for programs related to back muscle strengthening and correct body mechanics to help prevent this problem among OR nurses and, in turn, have a positive effect on patient outcomes.

\section{Limitations}

There are no known risks associated with participation in this study. Participants became frustrated while completing the survey but were able to stop and complete the survey later.

\section{Author note}

There were no direct benefits from participating in this study. The findings of this study will provide novel information about the prevalence and risk factors of low back pain among OR personnel, that may result in modifying the risk factors and providing a conducive environment. There was no financial assistance for this project.

This study has been approved by the institutional review board of the College of Nursing, Christian Medical College, Vellore. As per our fullest knowledge, there are no ethical concerns related to this study.

\section{References}

1. Deyo RA, Weinstein JN. Low back pain. N Engl J Med 2001;344(5):363-370.

2. Andersson GB. Epidemiological features of chronic low-back pain. Lancet 1999;354(9178):581-585.

3. Deyo RA, Tsui-Wu YJ. Descriptive epidemiology of low-back pain and its related medical care in the United States. Spine (Phila Pa 1976) 1987;12(3):264-268.

4. Taimela S, Kujala UM, Salminen JJ, Viljanen T. The prevalence of low back pain among children and adolescents. A nationwide, cohort-based questionnaire survey in Finland. Spine (Phila Pa 1976) 1997;22(10):11321136.
5. Balague F, Troussier B, Salminen JJ. Nonspecific low back pain in children and adolescents: Risk factors. Eur Spine J 1999;8(6):429-438.

6. Karahan A, Kav S, Abbasoglu A, Dogan N. Low back pain: Prevalence and associated risk factors among hospital staff. J Adv Nurs 2009;65(3):516-524.

7. Al Dajah S, Al DA. Prevalence and risk factors of low back pain among nurses in Sudayr region. ESJ 2013;9(33):198-205.

8. Cassidy JD, Carroll LJ, Cote P. The Saskatchewan health and back pain survey. The prevalence of low back pain and related disability in Saskatchewan adults. Spine (Phila Pa 1976) 1998;23(17):1860.

9. Skovron ML, Szpalski M, Nordin M, Melot C, Cukier D. Sociocultural factors and back pain. A population-based study in Belgian adults. Spine (Phila Pa 1976) 1994;19(2):129-137.

10. Katz JN. Lumbar disc disorders and low-back pain: Socioeconomic factors and consequences. J Bone Joint Surg Am 2006;88(Suppl 2):21-24.

11. Deyo RA, Loeser JD, Bigos SJ. Herniated lumbar intervertebral disk. Ann Intern Med 1990;112(8):598-603. DOI: 10.7326/0003-4819112-8-598

12. Croft PR, Papageorgiou AC, Ferry S, Thomas E, Jayson MI, Silman AJ. Psychologic distress and low back pain. Evidence from a prospective study in the general population. Spine (Phila Pa 1976) 1995;20(24):2731-2737.

13. Ouedraogo DD, Ouedraogo $V$, Ouedraogo $\mathrm{LT}$, Kinda $\mathrm{M}$, Tieno $\mathrm{H}$, Zoungrana $\mathrm{El}$ et al. Prevalence and factors associated with low back pain among hospital staff in Ouagadougou (Burkina Faso). Med Trop (Mars) 2010;70(3):277-280.

14. Moscato U, Trinca D, Rega ML, Mannocci A, Chiaradia G, Grieco G et al. Musculoskeletal injuries among operating room nurses: Results from a multicenter survey in Rome, Italy. J Public Health 2010;18(5):453-459.

15. Lin PH, Tsai YA, Chen WC, Huang SF. Prevalence, characteristics, and work-related risk factors of low back pain among hospital nurses in Taiwan: A cross-sectional survey. Int J Occup Med Environ Health 2012;25(1):41-50.

16. Sikiru L, Shmaila H. Prevalence and risk factors of low back pain among nurses in Africa: Nigerian and Ethiopian specialized hospitals survey study. East Afr J Public Health 2009;6(1):22-25.

17. Mohseni-Bandpei MA, Ahmad-Shirvani M, Golbabaei N, Behtash H, Shahinfar Z, Fernandez-de-las-Penas C. Prevalence and risk factors associated with low back pain in Iranian surgeons. J Manipulative Physiol Ther 2011;34(6):362-370.

18. Maul I, Laubli T, Klipstein A, Krueger H. Course of low back pain among nurses employed by a large university hospital in Switzerland: A longitudinal study across eight years. Occup Environ Med 2003;60(7):497-503.

19. Keriri H. Prevalence and risk factors of low back pain among nurses in operating rooms, Taif, Saudi Arabia. Am J Res Commun 2013;1(11):25.

20. Aljeesh Y, Nawajha SA. Determinants of low back pain among operating room nurses in Gaza governmental hospitals. J Al Azhar Univ Gaza (Nat Sci) 2011;14:41-54. 